\title{
Integration of Purkinje Cell Inhibition by Cerebellar Nucleo-Olivary Neurons
}

\author{
Marion Najac and Indira M. Raman \\ Department of Neurobiology, Northwestern University, Evanston, Illinois 60208
}

\begin{abstract}
Neurons in the cerebellar cortex, cerebellar nuclei, and inferior olive (IO) form a trisynaptic loop critical for motor learning. IO neurons excite Purkinje cells via climbing fibers and depress their parallel fiber inputs. Purkinje cells inhibit diverse cells in the cerebellar nuclei, including small GABAergic nucleo-olivary neurons that project to the IO. To investigate how these neurons integrate synaptic signals from Purkinje cells, we retrogradely labeled nucleo-olivary cells in the contralateral interpositus and lateral nuclei with cholera toxin subunit B-Alexa Fluor 488 and recorded their electrophysiological properties in cerebellar slices from weanling mice. Nucleo-olivary cells fired action potentials over a relatively narrow dynamic range (maximal rate, $\sim 70$ spikes/s), unlike large cells that project to premotor areas (maximal rate, $\sim 400$ spikes/s). $\mathrm{GABA}_{\mathrm{A}}$ receptor-mediated IPSCs evoked by electrical or optogenetic stimulation of Purkinje cells were more than 10-fold slower in nucleo-olivary cells (decay time, $\sim 25 \mathrm{~ms}$ ) than in large cells $(\sim 2 \mathrm{~ms})$, and repetitive stimulation at $20-150 \mathrm{~Hz}$ evoked greatly summating IPSCs. Nucleo-olivary firing rates varied inversely with IPSP frequency, and the timing of Purkinje IPSPs and nucleo-olivary spikes was uncorrelated. These attributes contrast with large cells, whose brief IPSCs and rapid firing rates can permit well timed postinhibitory spiking. Thus, the intrinsic and synaptic properties of these two projection neurons from the cerebellar nuclei tailor them for differential integration and transmission of their Purkinje cell input.
\end{abstract}

Key words: cerebellum; deep cerebellar nuclei; inferior olive; IPSC; IPSP

\section{Introduction}

Behavioral, anatomical, and computational studies have identified nucleo-olivary neurons of the cerebellar nuclei $(\mathrm{CbN})$ as playing a central role in driving acquisition and extinction of learned movements (Medina et al., 2002; Rasmussen and Hesslow, 2014). Like large CbN projection neurons, small GABAergic nucleo-olivary neurons are inhibited by Purkinje cells (ChanPalay, 1977; de Zeeuw et al., 1988; Teune et al., 1998), but project to the inferior olive (IO) rather than to premotor nuclei. Nucleoolivary cells inhibit their IO targets by releasing GABA asynchronously (Best and Regehr, 2009), thereby decreasing firing rates and reducing spike synchrony in the IO (Lefler et al., 2014). Climbing fibers from IO cells evoke complex spikes that slow Purkinje cell firing (Savio and Tempia, 1985), predicted to reduce inhibition onto all CbN projection neurons (Teune et al., 1998). Thus, nucleo-olivary neurons form a link in a trisynaptic negativefeedback loop that regulates cerebellar output.

\footnotetext{
Received Aug. 26, 2014; revised Nov. 10, 2014; accepted Nov. 13, 2014.

Author contributions: M.N. and I.M.R. designed research; M.N. performed research; M.N. and I.M.R. analyzed data; M.N. and I.M.R. wrote the paper.

This work is supported by NIH-NS39395 (to I.M.R.). We thank members of the Raman laboratory for helpful discussions and comments on this manuscript and Professor Ken Mackie of Indiana University for the kind gift of GAD67 knock-in mice. Confocal microscopy was performed in the Biological Imaging Facility of Northwestern University.

The authors declare no competing financial interests.

Correspondence should be addressed to Indira M. Raman, Department of Neurobiology, 2205 Tech Drive, Northwestern University, Evanston, IL 60208. E-mail: i-raman@northwestern.edu.

DOI:10.1523/JNEUROSCI.3583-14.2015

Copyright $\odot 2015$ the authors $\quad 0270-6474 / 15 / 350544-06 \$ 15.00 / 0$
}

Despite their key position in cerebellar circuits, understanding how nucleo-olivary cells convert synaptic inputs into spike outputs has been impeded by difficulty in identifying nucleoolivary cells. The population of "small" $\mathrm{CbN}$ cells is diverse, including nucleo-olivary cells, GABAergic-glycinergic interneurons, and inhibitory as well as excitatory neurons projecting to the cerebellar cortex (Uusisaari et al., 2007; Houck and Person, 2014; Husson et al., 2014). Studies of GFP-labeled GAD67expressing $\mathrm{CbN}$ neurons, which likely include some cells from all three categories, show that GAD67-GFP+ cells have mIPSCs with kinetics that are broadly distributed but generally slower than those of large cells, suggestive of distinct physiological properties of different CbN cells (Uusisaari and Knöpfel, 2008). How identified nucleo-olivary cells respond to inhibition specifically from Purkinje cells firing at different rates is still unknown. Because the interaction between intrinsic firing and IPSC time course can influence spike patterns of CbN cells (Person and Raman, 2012), defining these features in nucleo-olivary neurons may reveal how these cells process inhibitory signals.

We therefore retrogradely labeled nucleo-olivary cells and recorded their responses to optically and electrically evoked Purkinje-mediated inhibition. Relative to large cells, nucleoolivary cells had lower firing rates, narrower dynamic ranges, and smaller IPSCs with slower kinetics. The accumulation of inhibitory currents during repetitive stimuli made nucleo-olivary firing rates decrease monotonically with input rate. The distinct synaptic and intrinsic properties of nucleo-olivary cells thus let them report Purkinje firing rates integrated over a few hundred milliseconds. 

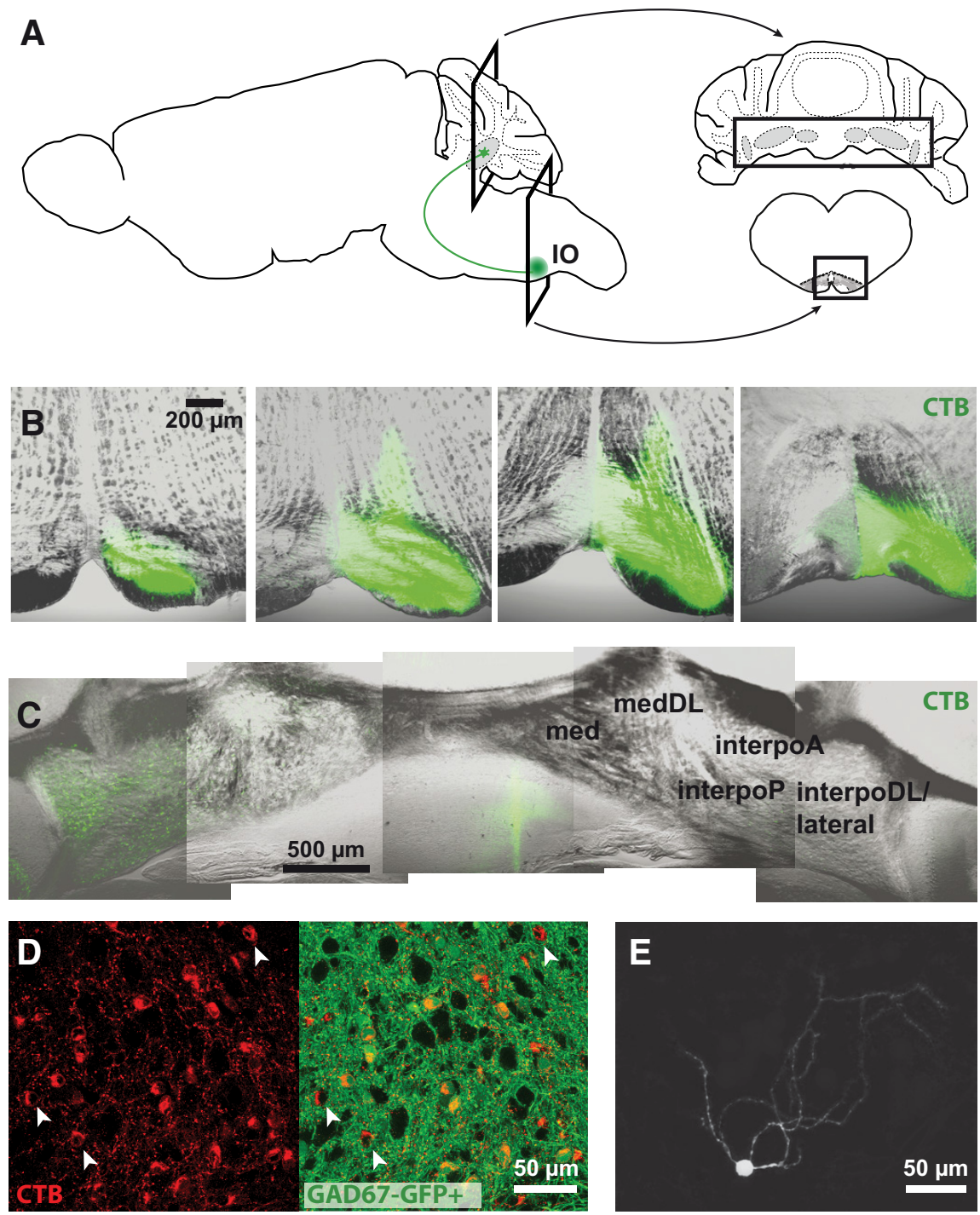

Figure 1. Retrograde labeling of nucleo-olivary neurons. $\boldsymbol{A}$, Schematics of the brain (left) showing the CbN (gray) and a nucleo-0livary cell (green) and coronal sections (right) of the cerebellum (top) and brainstem with 10 (bottom). Rectangles indicate sections in $\boldsymbol{B}$ and $\boldsymbol{C}$. $\boldsymbol{B}$, Confocal images of CTB injections (green) in the 10. Each image from left to right progresses $320 \mu \mathrm{m}$ rostrocaudally. $\boldsymbol{C}$, Retrograde labeling in the contralateral anterior and posterior interpositus nuclei (interpoA and interpoP), dorsolateral horn of the interpositus nucleus (interpoDL), and lateral nucleus but not medial nucleus (med) nor its dorsolateral horn (medDL). Montage of confocal images. D, Z-stack of confocal images showing labeled nucleo-olivary cells (red) in GAD67-GFP+ mice (GFP, green) in the lateral nucleus. Arrowheads, GAD67-GFP-negative nucleo-olivary cells. E, Z-stack of confocal images showing a biocytin-filled nucleo-olivary cell with sparsely ramified dendrites. Background is reduced to facilitate visualization of dendrites.

\section{Materials and Methods}

All experiments were approved by the Northwestern University Institutional Animal Care and Use Committee.

Retrograde labeling. P20-P30 mice of either sex [C57BL/6 (Charles River); Ai27DxPcp2-cre, in which channelrhodopsin hChR2(H134R) is expressed exclusively in Purkinje neurons (The Jackson Laboratory); or GFP-labeled GAD67 knock-in (Tamamaki et al., 2003)] were anesthetized with ketamine/xylazine ( 90 and $3 \mathrm{mg} / \mathrm{kg}$, i.p.). Mice were craniotomized and $0.25-0.5 \mu \mathrm{l}$ of cholera toxin subunit B coupled to Alexa Fluor 488 or Alexa Fluor 633 (CTB-Alexa; $2 \mathrm{mg} / \mathrm{ml}$ in saline; Invitrogen) was stereotaxically pressure injected at two sites (anteroposterior: 5.4 and $5.75 \mathrm{~mm}$ ) along the rostrocaudal axis of the IO (lateral: $400-450 \mu \mathrm{m}$; depth: $6.4-6.6 \mathrm{~mm}$ ). Mice recovered for $4-7 \mathrm{~d}$ before anatomical or physiological experiments.

Electrophysiology. Mice were anesthetized with isoflurane and decapitated. Cerebella were removed into ACSF $\left(35-36^{\circ} \mathrm{C}\right)$ containing the follow- ing (in mM): $123 \mathrm{NaCl}, 3.5 \mathrm{KCl}, 1.5 \mathrm{CaCl}_{2}, 1$ $\mathrm{MgCl}_{2}, 26 \mathrm{NaHCO}_{3}, 1.25 \mathrm{NaH}_{2} \mathrm{PO}_{4}$, and 10 glucose and oxygenated with $95 \% \mathrm{O}_{2} / 5 \% \mathrm{CO}_{2}$. Coronal or parasagittal slices $(270 \mu \mathrm{m})$ were cut on a VT1200 vibratome (Leica), incubated for 30-40 min at $34^{\circ} \mathrm{C}$ in ACSF, and then maintained at room temperature.

Slices were bathed in ACSF $\left(33-34^{\circ} \mathrm{C}\right)$ on the stage of a Zeiss Examiner D1 microscope with a TILL Photonics imaging system. Recordings were made with a Multiclamp 700B amplifier with pClamp software (Molecular Devices). Nucleo-olivary cells were identified by fluorescence and large $\mathrm{CbN}$ cells by somatic diameters of $20-25 \mu \mathrm{m}$. For whole-cell recordings, patch pipettes $(2-4 \mathrm{M} \Omega$ ) contained the following (in mM): $120 \mathrm{~K}$-gluconate, $2 \mathrm{Na}$-gluconate, $6 \mathrm{NaCl}, 2 \mathrm{MgCl}_{2}, 0.1 \mathrm{CaCl}_{2}, 1$ EGTA, $4 \mathrm{Mg}-$ ATP, 0.3 Tris-GTP, 14 Tris-creatine phosphate, 10 HEPES, and 5 biocytin, $\mathrm{pH} 7.36$, $\sim 290$ mOsm; measured uncorrected junction potential $6.5 \mathrm{mV}$. Access resistances were uncorrelated with IPSC decay times $\left(r^{2}=0.02\right.$, $n=35$ nucleo-olivary cells) and were $27 \pm 1$ $\mathrm{M} \Omega(n=94$ nucleo-olivary cells $)$ and $11 \pm 1$ $\mathrm{M} \Omega(n=32$ large cells $)$, predictive of $\sim 2$ and $9 \%$ voltage error, respectively. For cellattached recordings, pipettes contained HBS containing the following (in $\mathrm{mm}$ ): $145 \mathrm{NaCl}$, $3.5 \mathrm{KCl}, 1.5 \mathrm{CaCl}_{2}, 1 \mathrm{MgCl}_{2}$, and 10 HEPES, $\mathrm{pH}$ 7.36. Where indicated, $5 \mu \mathrm{M}$ DNQX, $10 \mu \mathrm{M}$ CPP, or $10 \mu \mathrm{M}$ SR95531 was added to ACSF to block AMPA, NMDA, or $\mathrm{GABA}_{\mathrm{A}}$ receptors.

Spontaneous firing and input-output curves were measured without holding current. Firing during IPSPs was studied with 0-100 pA hyperpolarizing current (mean, $35 \pm 6 \mathrm{pA}, n=22$ ) to set mean spontaneous rates at $10-30$ spikes/s (nucleo-olivary cells) or 50-100 spikes/s (large cells).

For electrical stimulation of Purkinje axons, an HBS-filled theta pipette driven by a stimulus isolation unit SIU-202 (Warner Instruments) was positioned $30-150 \mu \mathrm{m}$ from the recorded cell. For optical stimulation, 1-2 ms blue LED pulses (Doric Lenses) were targeted near the recorded cell with a cannula-coupled optic fiber (Thorlabs).

Histology. For CTB-Alexa visualization, mice were anesthetized with pentobarbital $(60$ $\mathrm{mg} / \mathrm{kg}$, i.p.) and perfused with $4 \%$ paraformaldehyde. Brains were fixed overnight in paraformaldehyde before sections $(80 \mu \mathrm{m})$ were cut and mounted. For biocytin-filled cells, slices were fixed overnight and permeabilized ( $1 \mathrm{~d})$ in Cy-5-conjugated streptavidin $(1 \mu \mathrm{g} / \mathrm{ml}$; Jackson ImmunoResearch). Confocal images were taken with a Zeiss LSM510 or Leica SP5 microscope.

Chemicals were from Sigma-Aldrich, except DNQX, CPP, and SR95531 (Tocris Bioscience).

Data analysis. Morphological measurements of fixed cells were made with ImageJ software. Capacitance was estimated from step-evoked voltage-clamp transients. Other voltage-clamp data were filtered off-line at $1-2 \mathrm{kHz}$ and analyzed with Igor Pro (WaveMetrics) with NeuroMatic packages and AxoGraph (AxoGraph Scientific). IPSC amplitudes and kinetics were measured from averages of $8-50$ sweeps. For eIPSC trains, SR95531-subtracted currents were analyzed. Decay time constants were estimated from mono-exponential fits (large cells) or weighted biexponential fits (nucleo-olivary cells). Data are presented as mean \pm SEM. Statistical significance was assessed with unpaired two-tailed $t$ tests 
A

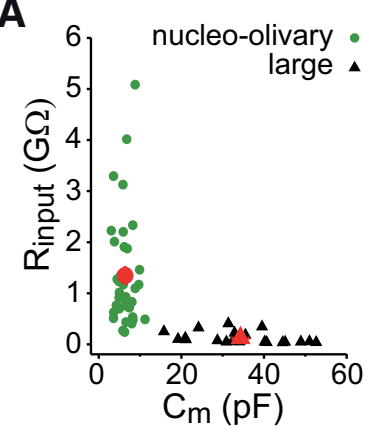

C
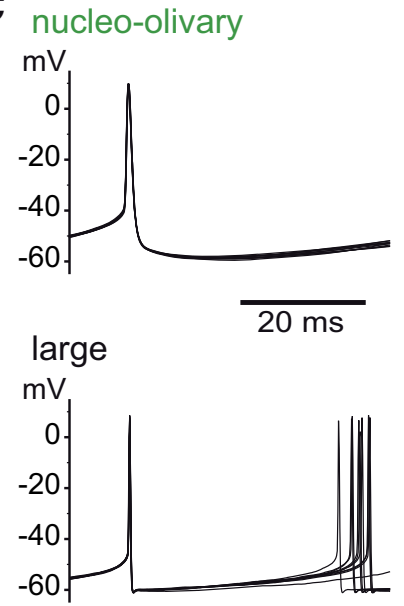

D
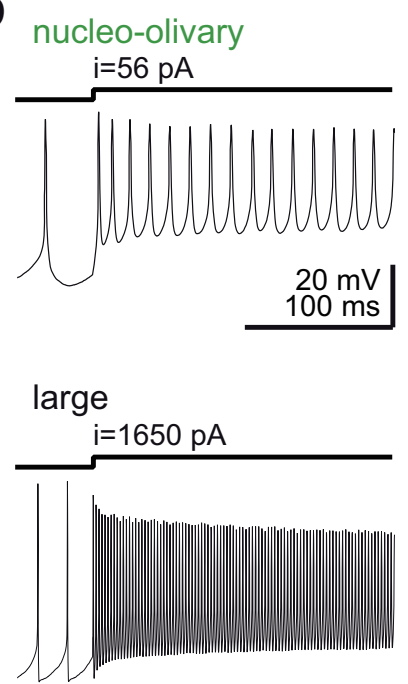

B

cell-attached recording
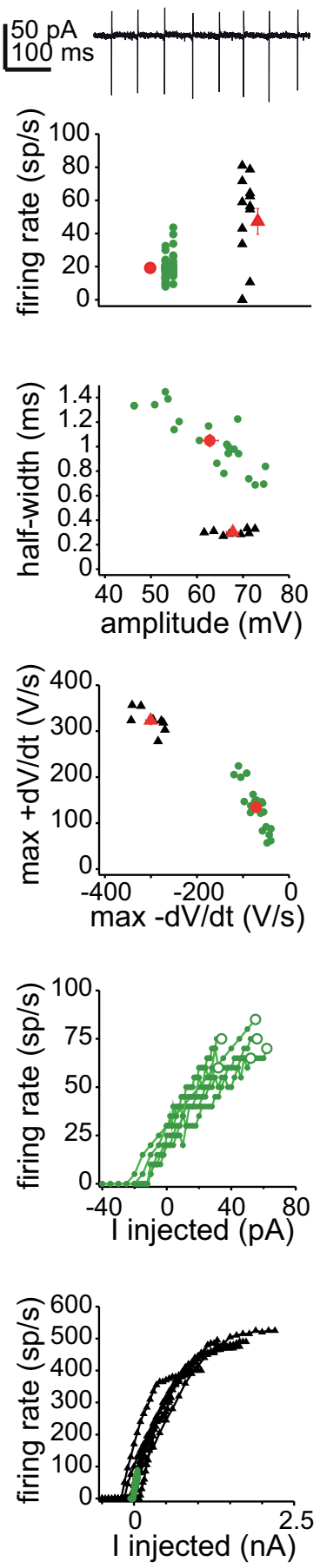

Figure 2. Comparison of intrinsic properties of nucleo-0livary and large CbN cells. $A$, Input resistance versus capacitance. Green circles, nucleo-olivary cells; black triangles, large cells; red symbols, means. $\boldsymbol{B}$, Spontaneous firing in cell-attached recordings. Top, Recording from a nucleo-olivary cell. Bottom, Spontaneous rates for all cells. C, Action potential waveforms. Left, Sample records. Ten superimposed traces for each cell. Right, Spike half-width versus amplitude (top); maximum positive slope ( $\max d \mathrm{dV} / \mathrm{dt}$ ) versus maximum negative slope (max $-\mathrm{dV} / \mathrm{dt}$ ). $\boldsymbol{D}$, Responses to step depolarizing currents. Left, Traces showing maximal firing rates: $75 \mathrm{~Hz}$ (top), $360 \mathrm{~Hz}$ (bottom). Right, Input- output curves. Open green circles indicate maximum injection for each response, i.e., larger injections produced depolarization block. Nucleo-olivary data are superimposed for comparison in the bottom.

or Rayleigh tests (Igor Pro). Stimulus artifacts from electrical trains have been reduced for clarity.

\section{Results}

\section{Identification of cells}

We retrogradely labeled nucleo-olivary somata by injecting CTBAlexa in the IO of anesthetized weanling mice (Fig. 1A,B). After 4-7 d, hundreds of fluorescent nucleo-olivary somata were visible in the contralateral interpositus, its dorsolateral horn, and the lateral nucleus (Fig. 1C,D). The contralateral location of fluorescent cells confirmed that labeling resulted from transport rather than leakage along the pipette track. Next, we tested the overlap of retrogradely labeled nucleo-olivary neurons with fluorescent cells in mice in which the GFP gene replaces one GAD67 allele $($ GAD67-GFP +$)$. In these mice, $38 \pm 2 \%$ of nucleo-olivary somata were not GFP labeled ( $n=3$ mice, $2344 / 6382$ cells in 410 sections; Fig. 1D), although nucleo-olivary cells are GABAergic (de Zeeuw et al., 1988). Thus, GAD67-GFP+ cells and nucleoolivary cells form intersecting but not overlapping populations. Moreover, GAD67 is also expressed in glycinergic CbN neurons (Tanaka and Ezure, 2004; Husson et al., 2014). Thus, the GAD67GFP + model neither uniquely nor fully labels nucleo-olivary cells, making retrograde labeling necessary to target exclusively the nucleo-olivary population.

\section{Morphology and intrinsic properties}

In cerebellar slices, CTB-Alexa-labeled cells filled with biocytin during recording and neighboring CTB-Alexa-labeled cells had small ovoid somata (long axis, $13.4 \pm 0.1 \mu \mathrm{m}$; short axis, $9.3 \pm$ $0.1 \mu \mathrm{m} ; n=27$ biocytin-filled, 457 unfilled; Fig. $1 E)$. Biocytinfilled cells had somatic areas of $108 \pm 4 \mu \mathrm{m}^{2}$ and few primary processes $(3.1 \pm 0.2, n=27)$. Thus, nucleo-olivary cells form a smaller sized population than GAD67-GFP+ cells $\left(150 \mu \mathrm{m}^{2}\right.$; Uusisaari et al., 2007). Consistent with their small size, nucleoolivary cells had high input resistances $(1.3 \pm 0.2 \mathrm{G} \Omega)$ and low capacitances $(6.4 \pm 0.3 \mathrm{pF}, n=38)$, significantly different from large $\mathrm{CbN}$ neurons $(119 \pm 22 \mathrm{M} \Omega ; 34 \pm 2 \mathrm{pF} ; n=24, p<0.0001$, both measures; Fig. 2A).

Nucleo-olivary cells fired spontaneous action potentials (cellattached, $19 \pm 1$ spikes/s, $n=51$; whole-cell, $27 \pm 3$ spikes $/ \mathrm{s}, n=$ 18 ) at rates lower than in large $\mathrm{CbN}$ cells (cell-attached, $47 \pm 8$ spikes/s, $n=13$; whole-cell, $92 \pm 17$ spikes/s, $n=8, p<0.01$, both measures; Fig. 2B). Action potential waveforms (Fig. 2C) had similar amplitudes in both cell types (nucleo-olivary, $63 \pm 2$ $\mathrm{mV}, n=22$; large, $68 \pm 1 \mathrm{mV}, n=8 ; p=0.4$ ) but were $\sim 3$-fold broader in nucleo-olivary cells (half-width, $1.05 \pm 0.05 \mathrm{~ms}$ ) versus large cells $(0.30 \pm 0.01 \mathrm{~ms}, p<0.0001)$. Consistent with their longer duration, action potentials in nucleo-olivary cells had slower upstrokes and downstrokes $(\max +\mathrm{dV} / \mathrm{dt}, 135 \pm 10 \mathrm{~V} / \mathrm{s}$; $\max -\mathrm{dV} / \mathrm{dt},-72 \pm 5 \mathrm{~V} / \mathrm{s})$ than in large cells $(\max +\mathrm{dV} / \mathrm{dt}$, $323 \pm 9 \mathrm{~V} / \mathrm{s} ; \max -\mathrm{dV} / \mathrm{dt},-301 \pm 11 \mathrm{~V} / \mathrm{s} ; p<0.0001$, both measures). In response to depolarizing current steps of progressively increasing amplitude, nucleo-olivary cells increased their firing rates linearly (to $72 \pm 4$ spikes/s, $n=6$ ) before undergoing depolarization block (Fig. 2D). In contrast, large cells had much higher maximal firing rates ( $415 \pm 44$ spikes/s, $n=7$; Fig. $2 E$ ). Thus, the dynamic range of nucleo-olivary cells is just over onesixth that of large cells.

\section{Kinetics of inhibitory synaptic inputs}

To compare the responses of nucleo-olivary and large cells to synaptic inhibition, we evoked IPSCs at $0 \mathrm{mV}\left(\mathrm{E}_{\mathrm{Cl}}=-74 \mathrm{mV}\right)$ in DNQX and CPP (Fig. 3A). In both cell types, IPSCs stimulated 

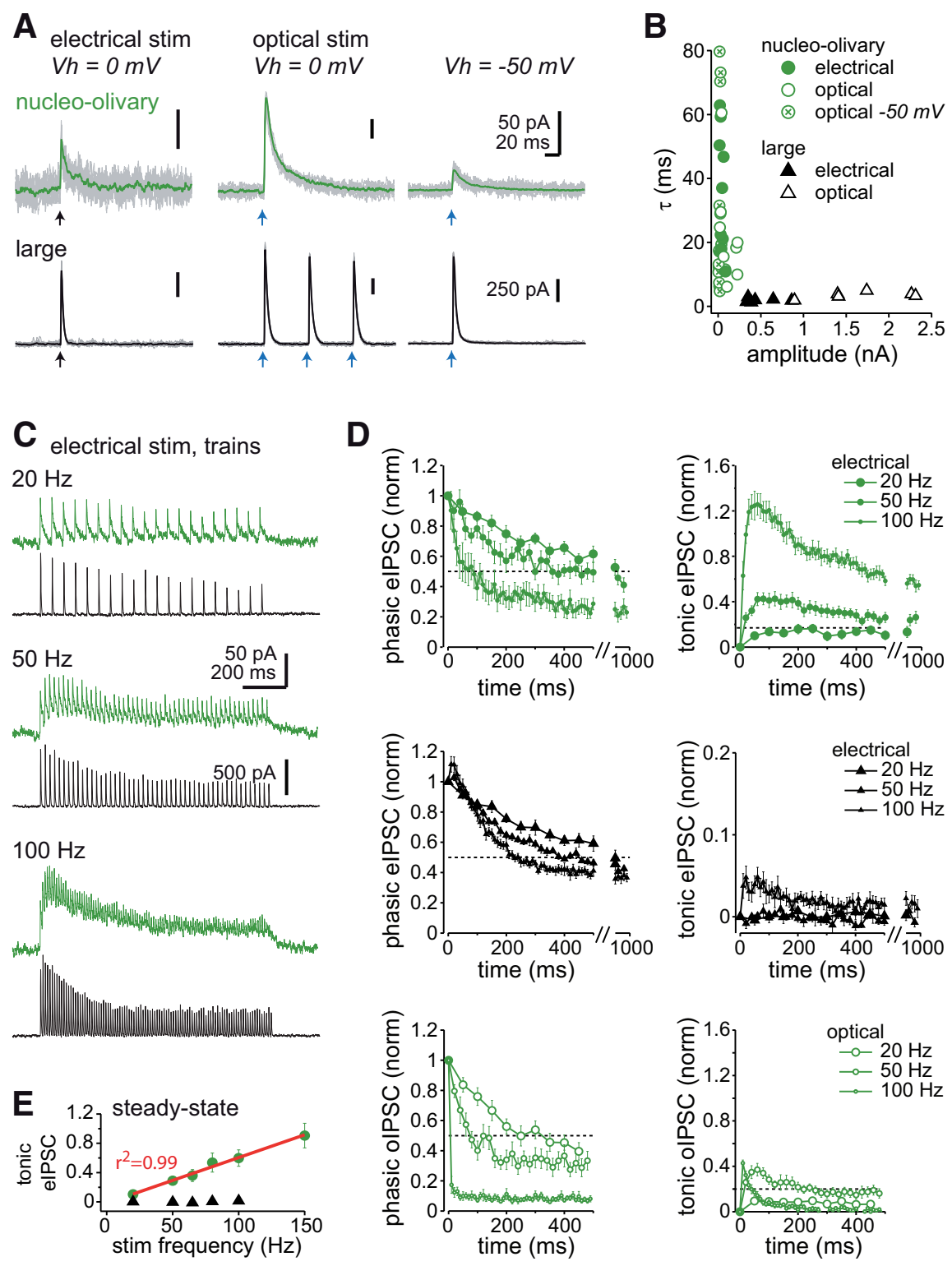

Figure 3. Comparison of IPSCs in nucleo-olivary and large cells. $A$, Left, Raw (gray) and mean (green, nucleo-olivary; black, large) evoked IPSCS. Records repeated in SR95531 were subtracted to reduce artifacts and isolate $G A B A_{A} R$-mediated current. Arrows indicate time of electrical or optical stimulation, as labeled. $\boldsymbol{B}$, Decay time constant $(\tau)$ versus IPSC amplitude. Open symbols, olPSCs; closed symbols, elPSCs. C, elPSCs evoked by $1 \mathrm{~s}$ trains of increasing frequencies, $V_{\mathrm{h}}=0 \mathrm{mV}$. D, Phasic (left) and tonic (right) elPSCs (top two parts) or olPSCS (bottom), normalized to the peak of IPSC $C_{1}$. Dotted lines are at 0.5 (left) and 0.2 (right) to facilitate comparison. $\boldsymbol{E}$, Steady-state tonic elPSCS versus stimulation frequency in nucleo-olivary and large cells ( $n \geq 6$, all points).

electrically (eIPSCs) were blocked by SR95531. As reported previously (Person and Raman, 2012), eIPSCs in large cells had an extremely brief decay time constant of $2.0 \pm 0.2 \mathrm{~ms}(n=6)$. Strikingly, eIPSCs in nucleo-olivary cells were $>16$ times longer, with decay times of $37 \pm 6 \mathrm{~ms}(n=9, p=0.0007$; Fig. $3 A, B)$, placing them near the opposite extreme of IPSC kinetics.

The amplitudes of eIPSCs likewise differed greatly. In large cells, even submaximal stimulus intensities evoked eIPSCs of $502 \pm 85 \mathrm{pA}(n=6)$. In contrast, the maximal eIPSC that could be elicited in nucleo-olivary cells was $43 \pm 8 \mathrm{pA}(n=9, p=0.001$; Fig. $3 A, B)$. Moreover, in one-third of nucleo-olivary cells (18/ 52 ), no eIPSCs were detectable, raising the possibility that not all inputs were successfully stimulated electrically.

To maximize recruitment of Purkinje afferents, we repeated the experiment in cerebellar slices with channelrhodopsin- expressing Purkinje cells. Blue light pulses elicited short-latency $(2.1 \pm 0.1 \mathrm{~ms})$ optically evoked IPSCs (oIPSCs) in nucleoolivary cells $(n=7)$, which were three times larger $(129 \pm 324 \mathrm{pA}, p=0.05)$ than eIPSCs (Fig. $3 A, B$ ), consistent with recruitment of additional afferents. Nevertheless, one-third of nucleo-olivary cells still lacked oIPSCs (22/68 cells), consistent with either loss of afferents during slicing or a lack of innervation. Like eIPSCs, oIPSCs had long decay time constants ( $23 \pm 7 \mathrm{~ms}, p=0.2$; Fig. $3 B$ ), confirming that slow synaptic responses arise from specifically activating Purkinje cells. Their larger size made oIPSCs detectable at $-50 \mathrm{mV}(n=19)$, with amplitudes of $22 \pm 4 \mathrm{pA}$ and decay times of $29 \pm 7 \mathrm{~ms}$ $(p=0.6)$. Rise times $(10-90 \%, 1.3 \pm 0.1$ ms) were uncorrelated with decay times $\left(r^{2}=0.08\right)$ suggesting that inadequate space clamp was not primarily responsible for the slow kinetics.

\section{Accumulation of tonic current during IPSC trains}

To quantify how IPSCs summate during repetitive stimulation, we evoked $1 \mathrm{~s}$ trains of eIPSCs at 20,50,65, 80, and $100 \mathrm{~Hz}$, and measured the current elicited by each stimulus (phasic IPSC) and the residual current before each stimulus (tonic IPSC), normalized to the peak of the first eIPSC $\left(\right.$ eIPSC $\left._{1}\right)$. In nucleoolivary cells, increasing stimulation frequencies evoked progressively more depression of phasic eIPSCs and larger tonic eIPSCs (Fig. 3C). The summation was so great that after $100 \mathrm{~ms}$ of $100 \mathrm{~Hz}$ stimuli, the tonic eIPSC $_{11}$ exceeded eIPSC $_{1}(121 \pm 19 \%, n=9)$, a 40 -fold larger relative amplitude than in large cells $(2.8 \pm 1.1 \%, n=6, p=0.0002$; Fig. $3 D$ ). In contrast, the phasic eIPSC ${ }_{11}$ was relatively smaller in nucleo-olivary cells $(39 \pm 8 \%)$ than in large cells $(78 \pm 4 \%$, $p=0.001$ ), possibly reflecting greater depression of GABA release and/or a ceiling effect from activating a common pool of receptors, as in large cells (Telgkamp et al., 2004).

Since Purkinje cells in vivo continuously fire $50-150$ spikes/s (Heck at al., 2007), the steady-state portion of the eIPSC train may be the most relevant physiologically. In nucleo-olivary cells, the amplitude of mean tonic current during the last $500 \mathrm{~ms}$ of stimulation (tonic eIPSC $\mathrm{Steady}_{\text {st }}$ ) increased linearly with stimulus frequency (Fig.

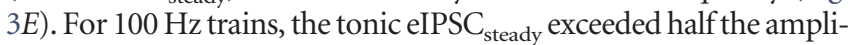
tude of eIPSC 1 (60 $\pm 11 \%)$ whereas in large cells it remained tiny $(1.5 \pm 0.8 \%)$. In contrast, the phasic eIPSC ${ }_{\text {steady }}$ was smaller in nucleo-olivary cells than in large cells, such that, at $100 \mathrm{~Hz}$, the tonicto-phasic eIPSC $\mathrm{C}_{\text {steady }}$ ratio was $2.0 \pm 0.3(n=8)$ in nucleo-olivary cells but only $0.03 \pm 0.02$ in large cells. Thus, tonic current seems likely to make nucleo-olivary cells integrate Purkinje signals over timescales of a few hundred milliseconds. 
Although optogenetic stimuli evoke large responses that can be unequivocally attributed to Purkinje cells, maximal effective stimulation rates are limited by channelrhodopsin kinetics. To test the responsiveness of hChR2(H134R) in Purkinje cells, we compared $500 \mathrm{~ms}$ trains of oIPSCs (Fig. 3D) to eIPSCs. At $100 \mathrm{~Hz}$, oIPSCs in nucleo-olivary cells depressed profoundly, such that little synaptic current was visible at the end of the train (phasic oIPSC $_{50}, 8 \pm 2 \%$ of oIPSC $1, n=$ 11 ), possibly because of channelrhodopsin desensitization, increase in release probability, and/or inactivation of presynaptic voltage-gated channels (Jackman et al., 2014). At $50 \mathrm{~Hz}$, however, phasic oIPSCs depressed only slightly more than eIPSCs (after 500 ms, oIPSC $25,33 \pm 6 \%, n=10$; eIPSC $\left._{25}, 50 \pm 5 \%, n=8, p=0.04\right)$, and accumulation of tonic current was comparable $\left(\mathrm{oIPSC}_{25}, 16 \pm 4 \%, n=11\right.$; eIPSC $\left._{25}, 23 \pm 4 \%, n=8, p=0.5\right)$. We therefore concluded that we could study oIPSCs for stimulus rates up to $50 \mathrm{~Hz}$.

\section{Nucleo-olivary cell firing follows the rate of IPSPs}

Next, we evoked eIPSP and oIPSP trains in current-clamped nucleo-olivary cells (Fig. $4 A, B$ ). Basal firing was maintained at $19 \pm 2$ spikes/s. During the first $100 \mathrm{~ms}$, electrical stimulation at $20 \mathrm{~Hz}, 50 \mathrm{~Hz}, 100$ $\mathrm{Hz}$, or $150 \mathrm{~Hz}$ reduced firing by $12 \pm 3 \%$, $26 \pm 4 \%, 57 \pm 8 \%$, or $64 \pm 7 \%(n=9,10$, $9,7, p<0.001$ all conditions), respectively (Fig. $4 C$ ). In these experiments, the stimulation intensity was reduced to avoid direct stimulation of recorded neurons, so these values likely underestimate maximal inhibition. Indeed, with optogenetic stimulation at $20 \mathrm{~Hz}$ or $50 \mathrm{~Hz}$, inhibition was two- to threefold more effective (Fig. 4C), reducing firing in this time window by $32 \pm$ 8 and $61 \pm 11 \%(n=8,8, p<0.001$, both conditions). Thus, even small-amplitude Purkinje IPSCs can efficiently inhibit nucleo-olivary cells. Notably, unlike large cells (Zheng and Raman, 2011), nucleoolivary cells showed no prolonged postinhibitory rebound firing. Instead, baseline firing rates were restored immediately after stimulation at all frequencies (Fig. 4A$C)$. Thus, nucleo-olivary cell firing has a simple relationship to real-time inhibition, with resumption of intrinsic rates occurring upon cessation of Purkinje input, regardless of history.

To account for standing synaptic depression of continuously active Purkinje cells, we measured mean firing rates over the last $500 \mathrm{~ms}$ of electrical stimulation (Fig. 4D). In this window, the drop in nucleo-olivary firing was similar with 20 and $50 \mathrm{~Hz}$ trains, falling by $10 \pm 2$ and $11 \pm 1 \%$, respectively. With higher frequencies, firing rates fell further, by $20 \pm 3 \%$ at $100 \mathrm{~Hz}$ and $28 \pm 4 \%$ clarity.
A

electrical stim, trains
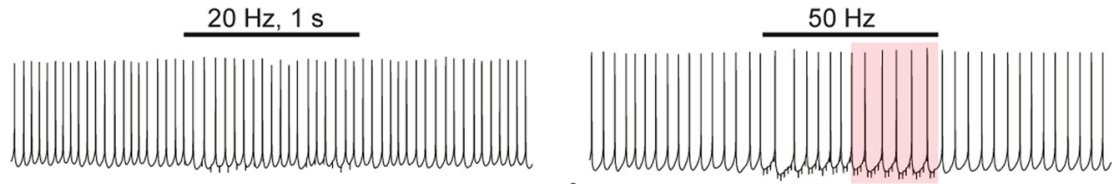

$20 \mathrm{mV}$

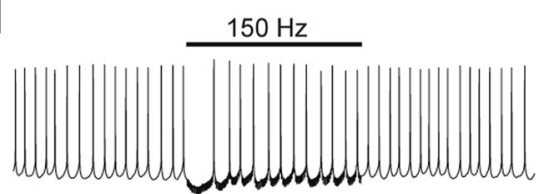

B

optical stim, trains
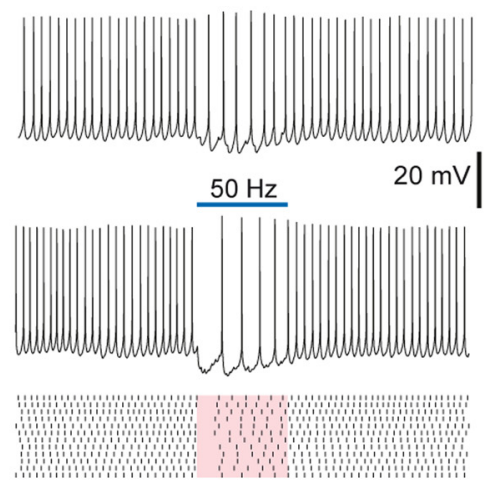

E

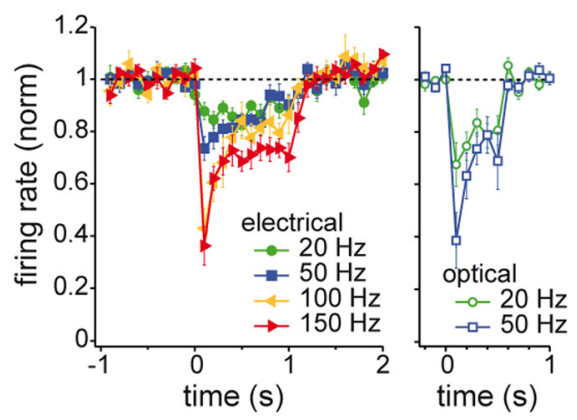

$50 \mathrm{~Hz}$ stim, superimposed cycles
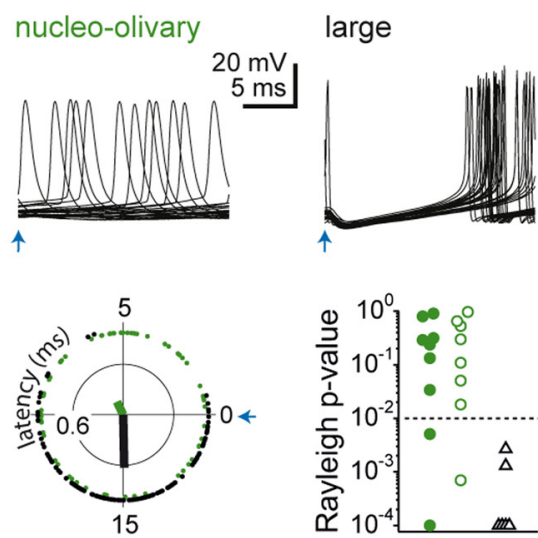

Figure 4. Synaptic inhibition of spiking in nucleo-olivary cells. $A$, Responses of a current-clamped nucleo-olivary cell to 1 s elPSP trains. Black lines, stimulus duration; pink shading, time window analyzed in E. B, Top and pink shading, As in $A$, for $0.5 \mathrm{~s}$ olPSP trains. Bottom, Raster plot of 12 trials for $50 \mathrm{~Hz}$ stimulation. C, Change in firing rate induced by elPSPs and olPSPs, measured in 100 ms time bins and normalized to baseline; $0 \mathrm{~ms}$, stimulus onset. $D$, Firing rate in the last $500 \mathrm{~ms}$ of stimulation versus electrical stimulation frequency (left) and tonic elPSC $C_{\text {steady }}$ from Figure $3 E$ (right). Gray shading illustrates range of spontaneous firing rates. $\boldsymbol{E}$, Top, 25 superimposed responses of a nucleo-olivary and a large cell to $50 \mathrm{~Hz}$ olPSPS, with stimulation times aligned at the blue arrow. Bottom, left, Polar plot of latency to each spike relative to an optical stimulus at $0 \mathrm{~ms}$. Green, nucleo-olivary; black, large cell. Thick lines, net vectors. Right, $P$ values for each cell from Rayleigh test indicating nonuniform ( $p<0.01$, dotted line) or uniform $(p>0.01)$ distribution. Open symbols, olPSPs; filled symbols, elPSPs. Five cells with $p<0.0001$ are plotted at $p=0.0001$ for

at $150 \mathrm{~Hz}(p<0.001$, all conditions; Fig. $4 D)$. For stimuli $>50$ $\mathrm{Hz}$, the steady-state reduction in firing rate, as well as the mean tonic eIPSC amplitude, increased linearly with stimulus frequency (Fig. 4D). Thus, to a first approximation, the degree of steady-state inhibition can be predicted directly from tonic current amplitudes.

The prolonged IPSCs of nucleo-olivary cells suggest that their action potentials may lack the capacity to phase-lock to inhibitory inputs, unlike fast IPSCs of large cells (Person and Raman, 
2012). We therefore examined the latency distribution of nucleoolivary spikes relative to each IPSP in a $50 \mathrm{~Hz}$ train (Fig. 4E) and assessed spike latency distributions throughout each $20 \mathrm{~ms}$ interstimulus interval. In large cells, with $500 \mathrm{~ms}$ trains, a uniform distribution was rejected in $6 / 6$ cells (Rayleigh test, $p<0.01$ ), consistent with a narrow window for spike latencies. In contrast, among nucleo-olivary cells, only $3 / 17$ cells had a preferred firing phase (Fig. 4E). Thus, nucleo-olivary cells are unlikely to transmit information about Purkinje cell spike timing, instead signaling in inverse proportion to the firing rate of their inhibitory afferents.

\section{Discussion}

These data demonstrate that identified nucleo-olivary cells in the mouse cerebellar nuclei form a population of small neurons with high input resistances, moderate firing rates, and prolonged Purkinje-mediated IPSCs. The slow IPSC kinetics generate significant temporal summation and the resulting accumulation of tonic inhibitory current effectively suppresses firing in approximate proportion to the rate of inhibitory input. Cessation of Purkinje input restores basal firing with no rebound. Nucleo-olivary cells can therefore integrate and report the recent history of Purkinje cell activity, which may be suited to their role in motor learning (Medina et al., 2002; Rasmussen and Hesslow, 2014).

GAD67-GFP + CbN neurons, which we find include a subset of nucleo-olivary neurons, have mIPSCs with decay constants averaging $\sim 10 \mathrm{~ms}$ but ranging up to $50 \mathrm{~ms}$ (Uusisaari and Knöpfel, 2008). Identified nucleo-olivary cells have evoked IPSCs that decay at the slow end of this spectrum (23-37 ms), consistent with their forming a subpopulation of the GAD67-GFP+ cells. The broad distribution of IPSCs even in identified nucleo-olivary cells may indicate different subcellular sites of input, spread of neurotransmitter, or a range of $\mathrm{GABA}_{\mathrm{A}} \mathrm{R}$ kinetics. Indeed, variable ratios of slowly gating $\alpha_{3}$-subunits and rapidly gating $\alpha_{1}$ subunits can generate a range of IPSC decay times (Eyre et al., 2012), and pharmacological manipulations provide evidence for expression of both subunits in GAD67-GFP+ CbN cells (Uusisaari and Knöpfel, 2008). Such receptor heterogeneity may slow IPSC kinetics of nucleo-olivary cells.

Regarding the site of inputs, one-third of nucleo-olivary cells lacked functional innervation from Purkinje cells. In the rat lateral nucleus, $48 \%$ of small neurons receive axosomatic synapses, mainly from Purkinje cells (Chan-Palay, 1977); approximately half of these cells are probably nucleo-olivary neurons (Husson et al., 2014). Thus, it is likely that in some nucleo-olivary neurons that we recorded, Purkinje input was restricted to the dendrites. In other cells, all dendritic afferents may have been lost during slicing, accounting for the lack of inputs. Still others may really lack Purkinje innervation.

Evidence from behavioral, anatomical, and pharmacological studies demonstrates that nucleo-olivary cells regulate associative learning by regulating spiking by IO cells, which transmit error signals from unconditioned stimuli to the cerebellar cortex. During acquisition of responses in delay eyelid conditioning, IO activity progressively decreases (Hesslow and Ivarsson, 1996), while the number of inhibitory synapses increases (Nicholson and Freeman, 2003). Conversely, IO activity is restored during extinction (Hesslow and Ivarsson, 1996), and blocking inhibition of the IO suppresses extinction (Medina et al., 2002). In computational models, nucleo-olivary modulation of climbing fiber activity is required for bidirectional cerebellar learning (Medina et al., 2002). The present data provide experimental constraints on the firing properties and synaptic responses of these neurons, setting the stage for further exploration of their role in synaptic and behavioral plasticity through experiment and simulation.

\section{References}

Best AR, Regehr WG (2009) Inhibitory regulation of electrically coupled neurons in the inferior olive is mediated by asynchronous release of GABA. Neuron 62:555-565. CrossRef Medline

Chan-Palay V (1977) Cerebellar dentate nucleus: organization, cytology, and transmitters. Berlin: Springer.

de Zeeuw CI, Holstege JC, Calkoen F, Ruigrok TJ, Voogd J (1988) A new combination of WGA-HRP anterograde tracing and GABA immunocytochemistry applied to afferents of the cat inferior olive at the ultrastructural level. Brain Res 447:369-375. CrossRef Medline

Eyre MD, Renzi M, Farrant M, Nusser Z (2012) Setting the time course of inhibitory synaptic currents by mixing multiple GABA(A) receptor $\alpha$ subunit isoforms. J Neurosci 32:5853-5867. CrossRef Medline

Heck DH, Thach WT, Keating JG (2007) On-beam synchrony in the cerebellum as the mechanism for the timing and coordination of movement. Proc Natl Acad Sci U S A 104:7658-7663. CrossRef Medline

Hesslow G, Ivarsson M (1996) Inhibition of the inferior olive during conditioned responses in the decerebrate ferret. Exp Brain Res 110:36-46. CrossRef Medline

Houck BD, Person AL (2014) Cerebellar loops: a review of the nucleocortical pathway. Cerebellum 13:378-385. CrossRef Medline

Husson Z, Rousseau CV, Broll I, Zeilhofer HU, Dieudonné S (2014) Differential GABAergic and glycinergic inputs of inhibitory interneurons and Purkinje cells to principal cells of the cerebellar nuclei. J Neurosci 34: 9418-9431. CrossRef Medline

Jackman SL, Beneduce BM, Drew IR, Regehr WG (2014) Achieving highfrequency optical control of synaptic transmission. J Neurosci 34:77047714. CrossRef Medline

Lefler Y, Yarom Y, Uusisaari MY (2014) Cerebellar inhibitory inputs to the inferior olive decreases electrical coupling and blocks subthreshold oscillations. Neuron 81:1389-1400. CrossRef Medline

Medina JF, Nores WL, Mauk MD (2002) Inhibition of climbing fibres is a signal for the extinction of conditioned eyelid responses. Nature 416:330 333. CrossRef Medline

Nicholson DA, Freeman JH Jr (2003) Addition of inhibition in the olivocerebellar system and the ontogeny of a motor memory. Nat Neurosci 6:532537. Medline

Person AL, Raman IM (2012) Purkinje neuron synchrony elicits time-locked spiking in the cerebellar nuclei. Nature 481:502-505. CrossRef Medline

Rasmussen A, Hesslow G (2014) Feedback control of learning by the cerebelloolivary pathway. Prog Brain Res 210:103-119. CrossRef Medline

Savio T, Tempia F (1985) On the Purkinje cell activity increase induced by suppression of inferior olive activity. Exp Brain Res 57:456-463. CrossRef Medline

Tamamaki N, Yanagawa Y, Tomioka R, Miyazaki J, Obata K, Kaneko T (2003) Green fluorescent protein expression and colocalization with calretinin, parvalbumin, and somatostatin in the GAD67-GFP knock-in mouse. J Comp Neurol 467:60-79. CrossRef Medline

Tanaka I, Ezure K (2004) Overall distribution of GlyT2 mRNA-containing versus GAD67 mRNA-containing neurons and colocalization of both mRNAs in midbrain, pons, and cerebellum in rats. Neurosci Res 49:165178. CrossRef Medline

Telgkamp P, Padgett DE, Ledoux VA, Woolley CS, Raman IM (2004) Maintenance of high-frequency inhibitory transmission at Purkinje to cerebellar nuclear synapses by spillover from boutons with multiple release sites. Neuron 41:113-126. CrossRef Medline

Teune TM, van der Burg J, de Zeeuw CI, Voogd J, Ruigrok TJ (1998) Single Purkinje cell can innervate multiple classes of projection neurons in the cerebellar nuclei of the rat: a light microscopic and ultrastructural tripletracer study in the rat. J Comp Neurol 392:164-178. CrossRef Medline

Uusisaari M, Knöpfel T (2008) GABAergic synaptic communication in the GABAergic and non-GABAergic cells in the deep cerebellar nuclei. Neuroscience 156:537-549. CrossRef Medline

Uusisaari M, Obata K, Knöpfel T (2007) Morphological and electrophysiological properties of GABAergic and non-GABAergic cells in the deep cerebellar nuclei. J Neurophysiol 97:901-911. CrossRef Medline

Zheng N, Raman IM (2011) Prolonged postinhibitory rebound firing in the cerebellar nuclei mediated by group I metabotropic glutamate receptor potentiation of L-type calcium currents. J Neurosci 31:10283-10292. CrossRef Medline 